\title{
The effect of silane treated fibre loading on mechanical properties of pineapple leaf/kenaf fibre filler phenolic composites
}

\begin{abstract}
The aim of the present study is to investigate mechanical and morphological properties of pineapple leaf fibres (PALF) reinforced phenolic composites and its comparison with kenaf fibre $(\mathrm{KF}) /$ phenolic composites. Mechanical properties (tensile, flexural and impact) of untreated and treated PALF phenolic composites at different fibre loading were investigated. Tensile, flexural and impact properties of PALF and kenaf/phenolic composites were analyzed as per ASTM standard. Morphological analysis of tensile fracture samples of composites was carried out by scanning electron microscopy. Obtained results indicated that treated PALF/phenolic composites at 50\% PALF loading exhibited better tensile, flexural and impact properties as compared to other untreated PALF/phenolic composites. Treated kenaf/phenolic composites at 50\% fibre loading showed better tensile, flexural and impact properties than untreated kenaf/phenolic composite. It is concluded that treated 50\% fibre loading kenaf and PALF/phenolic composites showed better mechanical properties than untreated kenaf and PALF/phenolic composites due to good fibre/matrix interfacial bonding. Results obtained in this study will be used for the further study on hybridization of PALF and KF based phenolic composites.
\end{abstract}

Keyword: Pineapple leaf fibres; Kenaf fibres; Phenolic composite; Mechanical properties; Morphological properties 